\title{
ENVIRONMENTAL POLICY AND LEGISLATION IN NATIONAL PARKS THE CASE OF PARNASSOS, GREECE
}

\author{
Athina Zikouli ${ }^{1^{*}}$, Zacharoula Andreopoulou ${ }^{1}$ \\ ${ }^{1 *}$ School of Forestry and Natural Environment, Aristotle University of Thessaloniki, \\ Box 247, 54124 Thessaloniki, Greece; \\ "Corresponding Author Athina Zikouli, e-mail:azikouli@for.auth.gr; randreop@for.auth.gr;
}

Received May 2020; Accepted June 2020; Published July 2020;

DOI: https://doi.org/10.31407/ijees10.305

\begin{abstract}
National Forest Parks are part of the unique places known as protected areas in respect of their complex ecosystems. Therefore, a sustainable forestry policy is essential so as to implement regionalism in these ecosystems. The organization of National Forest Parks commenced in Greece in 1938. Throughout an 80 year period: one presidential decree and eight Greek laws have regulated the protected areas. Now, it is clear that policy has been reshaped rapidly unfortunately not effectively. In examining further the period of national policy enactment, it is essential to understand whether either political change or difficult circumstances have arisen that have demanded a policy response. This study aims to evaluate the political reform by implementing a two way policy analysis approach firstly, so as to examine the legislative initiatives of previous years, including the new legislation or changes in the existing policy in relation to National Forest Parks and secondly, to estimate whether the policy was created according to political change and forthcoming elections or in consideration of the natural disasters in this country. The methodology is based on a case study for Mt. Parnassos recording how regional development has been promoted through the past years. The conclusions of this research can be helpful to the responsible authorities and parties within the development of a sustainable forestry policy, aiming both to preserve biodiversity and to reinforce the local economy.
\end{abstract}

Keywords: environmental policy, Greek legislation, regional development, Parnassos National Park 